\title{
The Exploitation of Caring Communities: The Elder Care Crisis in Germany
}

\author{
Tine Haubner, Friedrich Schiller University of Jena, Germany
}

\begin{abstract}
Against the background of a crisis of elder care in Germany, this article examines the expansion of informal elder care work in terms of exploitation. A concept of indirect exploitation is used that takes into account the special characteristics of highly feminised elder care work and Germany's elder care market. The article shows, through an empirical qualitative case study, that Germany's elder care regime is maintained through the politically supported exploitation of socially vulnerable population groups in favour of lowering the costs of social reproduction in an ageing capitalist society.
\end{abstract}

\section{KEYWORDS}

exploitation; informal elder care; care regime Germany; social policy; social reproduction

\section{Introduction}

Relatives administer tube feeds, a former nursery school teacher sets injections as a "volunteer dementia assistant", unskilled assistants wash patients requiring intensive care and a Bulgarian dressmaker engages in unpaid night watches for months to prevent a woman with dementia from running away - what is going on in Germany's elder care regime? These examples are taken from the empirical findings of a study guided by the following question: How does it come about that more and more laypersons perform elder care work for which they are neither qualified nor adequately paid? The study was based on the observation that, under the pressure of increasing demands, a shortage of skilled labour and cost-saving measures, there has been increased political support for informal elder care performed by four specific groups: relatives, volunteers, unemployed low-skilled persons and migrant care workers.

In Germany, the number of elderly dependents is predicted to rise to 3.4 million by 2030, with 506000 professional care workers needed (Prognos, 2012). One way to meet this rising demand would be to increase formal professionalised elder care, including upgrading existing low-paid care work. However, the German welfare state does not provide sufficient security and continues to rely on low wages in the elder care sector. In this context, the supply of qualified elder care workers is not keeping up with the increasing demand. In response, informal elder care that deviates from the standards of formally paid and regulated care work, has received political support since the 1990s. This has to do with the specific features of Germany's elder care regime. This regime can be called "family-based" because it delegates most of its elder care obligations to families, and, due to traditional gender-specific divisions of care work, particularly to women. Thus, it is largely based on informal and unpaid elder care work done by female relatives who are still Germany's most numerous and cheapest care providers. However, this care regime has run into difficulty, as unpaid female care work is becoming scarcer at precisely the time that the elder care burden is increasing. 
Rising female employment and the requirements of workplace flexibility as well as changed household and family structures lead to shrinking elder care potentials in many families. In an ageing capitalist society, elder care policy now tries to meet these challenges through the continuation of a cost-saving care regime under changing conditions of social reproduction. Under the heading of so-called "caring communities", supply gaps have triggered an intense socio-political search for the "dormant potentials" of cheap informal lay care beyond the family. In order to use informal care potentials, the government has attempted to fill the gaps by setting up cash-for-care programmes for families, strengthening volunteer care work, creating workfare programmes for unemployed and low-skilled workers, and legalising domestic care work done by migrants. All these groups have something in common: They are socially vulnerable and generate little or no personnel costs. Based on the study, the central thesis of this article is that the mobilisation and utilisation of informal elder care work can best be described as an exploitative political strategy because certain actors take advantage by appropriating the labour power of socially vulnerable caregivers in order to reduce rising reproduction costs.

The term exploitation refers to a specific causal nexus between two actors. As Erik Olin Wright (1997: 10) puts it, "the core of the concept revolves around a particular type of antagonistic interdependency of material interests". Accordingly, one actor exploits another if he or she can generate advantages at the other person's expense by appropriating their labour efforts. Exploitation is thus understood here as a process in which certain actors are able, under certain conditions, to use the (care-)working capacity of socially vulnerable actors to lower the costs of the reproduction of labour. Employers derive monetary benefits from the use of unskilled and informally working lay caregivers. They benefit from low contributions to long-term care insurance, which can be kept at a low level because a large proportion of care work is informal and unpaid. To put it in Marxist terms, comparable with the production of "relative surplus-value" (Marx, 1887: 219ff.), the use of informal elder care work reduces reproduction costs, thereby lowering the value of labour power and wages, and thus helping to appropriate more surplus to increase profit margins proportionally. Furthermore, providers of outpatient and inpatient care can also use the deployment of informal care workers to maintain their care provision under conditions of high cost pressure and a shortage of skilled care workers. By expanding informal lay care, the state also benefits from keeping care costs low to secure competitive advantages. What distinguishes this exploitation from Marx's concept of exploitation, is that 1) no formal wage labour is exploited, but 2) "unproductive" informal care work is predominantly performed in private households, and it is 3) not aimed directly at generating profits. Instead, it can be described as "indirect exploitation" because it aims to lower reproduction costs in order to indirectly maximise profits and to ensure the maintenance of an elder care regime oriented towards cost reduction even in times of rising demand.

By using the notion of exploitation, which has long since disappeared from German social sciences, the study takes an unconventional perspective. The notion of exploitation can help us to analyse the socio-politically driven use of informal elder care in at least two ways: First, it highlights the contemporary but hardly explored issue of national care policy from a critical perspective and identifies the structural causes, mechanisms and beneficiaries of a specific use of elder care work. Second, it explores the meaning of a core notion of Marxian theory by placing it in a rather unusual context. By doing so, it tries to extend the notion of exploitation beyond the traditional scope of paid employment and direct profit generation in order to understand the importance of unpaid care work for contemporary ageing capitalist societies.

The article is structured as follows: The next section discusses the situation of elder care in Germany in more detail. The following sections then present an analytical framework which can 
be used to investigate the exploitation of informal care work, using Marxist and Marxist-Feminist arguments. Thereafter, the core findings of a study on the causes, mechanisms, sufferers and beneficiaries of the exploitation of informal lay care in Germany are presented and analysed. Finally, the paper concludes by diagnosing a "cascaded" exploitation of informal elder care.

\section{The "Double Privatisation" of Elder Care}

In Germany, rising employment rates of women and rising elder care demands have been accompanied by a process of "double privatisation" since the 1990s (Biesecker et al., 2007). On the one side, privatisation appears in the guise of an ongoing growth of formal and commercial elder care services. Long-term care insurance has opened elder care to the market and thus initiated this process of privatisation. But commodification is only one side of the coin. On the other side, a second privatisation process takes place through an increasing shift of informal elder care back to private households and civil society. On the level of socio-political discourse, this is promoted by the concept of "caring communities", which aims at the greater involvement of civil society in elder care. According to this model, in times of increasing care requirements, a greater proportion of elder care should be distributed to communities as part of a "welfare mix" of professional, family and voluntary assistance (Powell, 2007). However, the mobilisation of informal elder care does not stop with voluntary care work. In order to meet the growing need for elder care, low-skilled and informal employment segments are being expanded, too. Thus, both unpaid informal and paid informal elder care work are politically promoted.

Informality is a relational concept that is always constituted vis-à-vis the socially valid norm of formally regulated wage labour and characterised by extra-legal regulation (Mayer-Ahuja, 2012: 291f.). The informalisation of work means deregulated employment norms or arrangements that deviate from the standards of formal work. In that regard, informal elder care can be care work without a contractual basis or an arrangement in which contractual regulations are violated.

With regard to the "double privatisation", we can distinguish two different sectors of informal elder care work in Germany, which are both politically strengthened: In "sector 1" - paid inpatient and outpatient care - the norm of formally regulated care work is undermined by the informal use of unskilled auxiliary staff and so-called "additional personal assistants". The latter are subsidised by the state and paid by the long-term care insurance fund rather than by private employers. These workers are trained in fast-track procedures and are officially used in overburdened inpatient and outpatient facilities for the care of dementia patients. However, they often perform care activities for which they are neither qualified nor paid. In addition, this category of paid informal elder care also includes migrant care workers whose labour in private households is promoted with the help of active policies by the state and whose labour rights are respected neither by placement agencies nor private employer households.

In "sector 2" - unpaid domestic care provision - there is not a weakening of regulated labour standards. State policy interventions aim, on the one hand, at the continuation of family care ${ }^{1}$ and, on the other hand, the inclusion of non-family, in-house support by volunteers. Training courses are available for volunteers, financed by the long-term care insurance fund; they receive an expense

\footnotetext{
${ }^{1}$ For example, the state restricts access to residential care facilities. These interventions have been very successful: In 2017, about three-quarters of all patients (76 per cent or 2.59 million) were provided with informal home care by relatives only (Statistisches Bundesamt, 2018).
} 
allowance of between 5 and 10 Euros an hour. No employment contracts apply in this sector, and the legal regulations that prohibit elder care activities for volunteers are often disregarded without sanction. So, these volunteers often take over care tasks for which they are not qualified. ${ }^{2}$

It is no coincidence that both sectors are currently being expanded: Despite all the differences between paid and unpaid elder care work considered here, both sectors are informal and do not aim at directly generating profits. The informal use of labour is characterised by a disregard for labour law regulations (such as qualification and wage standards). Thus, it is especially suitable for keeping down rising reproduction costs in the context of demographic change and the shortage of skilled workers. This is even more so as these workers are used illegally and replace formally employed professionals.

\section{Exploitation in a Welfare Market}

In order to empirically investigate the exploitative use of informal elder care workers, a concept of exploitation is needed. Additionally, the study would have to show a) why these population groups are exploited, b) which mechanisms do this, and c) to whose advantage it is. This is challenging, as the concept of exploitation is still associated with the explanation of direct (often industrial capitalist) profit generation. Using informal elder care work as an example introduces some challenges that are related to the special features of elder care in Germany.

First, care work cannot mainly be defined as "productive" labour according to a Marxian understanding. In comparison to the production of commodities, it has only limited profitability, as do all personal services due to their labour content - that is, the "human element [is] not readily replaceable by machines" (Baumol, 2012: 19). Even if it could be considered productive in a Marxian sense when it is done as formal and rationalised wage labour in private care groups that aims at the generation of profits (which is not the focus here), it has only limited profitability compared to other economic sectors. Above all, in Germany it is predominantly performed informally without pay in private households. But this fact is at least indirectly related to reasons of profit generation: By allowing the majority of elder care work to be performed informally, unpaid or underpaid, the German care regime reduces reproduction costs in an ageing society.

Second, elder care is performed in very special markets. The German market for elder care is a highly state-regulated "quasi-" or welfare market ${ }^{3}$ in which prices are determined by a specific downward cost pressure on wages and household incomes, induced by public long-term care insurance. With the introduction of long-term care insurance in 1995, not only was a market for elder care created but a budget principle was introduced. This was a novelty for the long tradition of fully comprehensive social insurance in Germany. Due to political pressure from employers, the insurance was introduced as only partial coverage with a low contribution rate. Thus, the insurance creates a specific cost pressure that determines the financial volume for insurance benefits and wages in advance. And these limits are significant: While the contribution rate for health insurance paid by employers and employees is 14.6 per cent, the rate for long-term care insurance is only 3.05

\footnotetext{
2 Volunteering in elder care is becoming increasingly qualified, and there are legal regulations prohibiting volunteers from carrying out special elder care activities (such as wound care). However, these regulations are often not observed in private households, and are not checked.

${ }^{3}$ By using the term welfare market, it is not claimed here that the rules of capitalist accumulation are suspended. Nevertheless, it is not only the logic of capitalist markets that governs here but also the logic of state-regulated welfare production (Bartlett, Roberts and Le Grand, 1998).
} 
per cent. Since then, the basis for remuneration for elder care services has been provided by restricted financial rates for inpatient care and so-called "point values" for outpatient care. These are negotiated between providers and insurance funds; they define the range of possible wage payments to care staff, and limit the purchasing power of households. As for other welfare markets, it can therefore apply that "consumer purchasing power is not expressed in money terms. Instead, it takes the form of an earmarked budget or 'voucher' confined to the purchase of a specific service" (Le Grand, 1991: 1260). Thus, low insurance benefits force private households to use the cheapest possible care providers, which in turn counters cost pressure through wage savings. The elder care market also differs from other markets because many small-scale care providers, such as the care services examined here, do not exist primarily to generate profits. Instead, their aim is to remain in the black under the high cost pressure. Thus, low wages in the elder care sector often do not result from cost-cutting imperatives for the purpose of maximising profits but from limited public funds.

Finally, elder care in Germany is still regarded a "semi-profession" (Etzioni, 1969) or a "Jane Doe job" for which one does not need any proper qualification, but only "female virtues" such as helpfulness and empathy. This feminisation refers to both unpaid domestic elder care work, which is considered a natural labour of love, and paid elder care, where wages and social recognition are low.

It follows that we are dealing here with forms of indirect exploitation. In the cases studied, it is not exploitation for the purpose of direct profit generation. However, by appropriating informal unpaid or (through the violation of labour regulations) underpaid elder care work, the costs of reproduction are kept low. We thus need a concept of exploitation that, regarding the cases examined here, first, should not depend upon assumptions about the direct creation of profits, and second, takes the identity and the similarities between the population groups addressed by care policy into account. In order to meet these requirements, Erik Olin Wright's concept of exploitation as well as terms and arguments from the Marxist-Feminist domestic labour debate will be now taken up.

\section{Marx's Blind Spots and the Exploitation of Unpaid Care Work}

According to Marx, profit is solely rooted in the specific feature of labour power to produce more value than is necessary for its reproduction. In addition, only "productive" labour, as a source of surplus value and profit, is considered to be capitalistically exploited. And this brings us to three problems that Marx's notion of exploitation poses for our analysis. First, Marx did not reflect at all upon the exploitation of (unpaid) care work. He equated the reproduction of labour power with the production of the goods consumed by the workforce. When writing about the "given quantity of the means of subsistence" (Marx, 1887: 121), he did not mention unpaid reproductive work (such as, the preparation of purchased foods). ${ }^{4}$ Second, he treated labour as average labour regardless of gender and skill. This assumption obscures a highly gender-segregated labour market and gender-based discrimination, which needs to be especially considered within the field of care work. Although Marx condemned patriarchal relations, he "left the question of gender un-

\footnotetext{
${ }^{4}$ Silvia Federici (2009: 292) also wrote that elder care marks the limits of Marxism: As reproductive work, it is not only unrecognised as work, but, in contrast to the reproduction of "productive" labour, it is also considered a value-absorbing activity.
} 
theorized partly because 'women's emancipation' had a peripheral importance in his political work, $\ldots$ and $\ldots$ he idealized industrial labour as the normative form of social production and a potential leveler of social inequalities" (Federici, 2017: 20). Finally, Marx's perspective, which "focuses attention on capital's exploitation of wage labor in commodity production", is problematic due to its marginalisation of informal, unfree and illegal use of labour which he tended to regard as outdated forms of pre-capitalist exploitation (Fraser, 2016: 165).

But what we can derive from Marx is that care work is always in crisis in capitalist societies due to its "unproductive" character, and although capitalist exploitation often looks like a free and fair exchange, it is always based on power and exclusion. To put it sociologically: For Marx, social vulnerability through social exclusion marks the precondition of exploitation in all class societies.

Since Marx did not reflect upon the importance of informal paid and unpaid care work for the reproduction of labour power, he thus failed to integrate the possibility of the exploitation of "unproductive" or even uncommodified care work. These shortcomings were controversially discussed in the 1970s within the feminist domestic labour debate, without which thinking about the capitalist exploitation of care work would be impossible. The significance of the debate for the present analysis lies foremost in its critique of economic reductionism and the use of Marx' notion of exploitation for unpaid domestic work. Since the nineteenth century, the socio-historical background of the debate was the nuclear family, traditionally composed of a paid male breadwinner and an unpaid housewife. German feminists Gisela Bock and Barbara Duden (1977) deciphered this institution as a genuinely capitalist form of organisation of the (re)production of (mostly male) labour power. Accordingly, unpaid domestic care work allows for the (re)production of labour power such that capital accumulation can satisfy demands for higher wages through the family wage, and thus enables an institution that relatively lowers the wage of the male breadwinner. Reproductive labour is an invisible part of the value of labour power and thus of profits. Without unpaid domestic labour, the value of labour power would be higher and this in turn would affect profits. Furthermore, the exploitation of free labour is thus comparatively more intensive than if domestic labour was commodified. Given these conclusions, it is conceivable that even unpaid work can be considered capitalistically exploitable, at least indirectly.

Feminist criticism delivered two major insights on exploitation relevant to our investigation. First, the hypothesis that capitalist exploitation can occur even when neither "productive work" nor work contracts nor remuneration exist led to a conceptual broadening of the notion of exploitation that untied it from the link to direct forms of profit generation. Furthermore, in the domestic labour debate, this indirect form of exploitation is aimed at the reproduction of usable labour power free of charge for capital. In the case of elder care, we need to rethink because elder care does not aim at the direct reproduction of usable labour power. Persons in need of elder care no longer constitute usable labour power. However, by carrying out elder care work mainly informally and cost-effectively, the reproduction costs of the workforce can be kept low. Without this informal care work, the contributions to long-term care insurance and thus the value of labour power would be much higher. To sum up, unpaid elder care as "unproductive" work does not itself generate profits. But instead of disregarding the exploitation of care work, feminists recognised the importance of unpaid care work for the lowering of reproduction costs and the resulting indirect contribution to profit generation.

Second, Marxist-Feminists take seriously the importance of sexist and racist discriminatory practices and the persistence of gender- and race-based oppression as "distinctly non-functionalist" and economically relevant factors. This "relationship between exploitation and oppression" (Bhattacharya, 2017: 3) - that is, the devaluation of feminised care work and its exploitative appropriation - is therefore possible because it is still considered a natural free resource or a "Jane 
Doe job" for which one does not need proper qualifications.

Related to the first insight, we can borrow a term from the domestic labour debate that addresses the indirect form of profit generation through the devaluation of reproduction costs. Rainer Bauböck (1988: 17f) grasped this as "depreciation" (Wertminderung, author's own translation). With the expansion of domestic work, capital is therefore able to indirectly reduce the value of labour power. Accordingly, domestic work is not a commodified labour activity and the specific "surplus" is not a positive quantity but a negative difference. "Depreciation" marks this negative difference and is a term that can be utilised in the sphere of informal elder care work, too. Although keeping labour costs low is a fundamental characteristic of capitalism, the depreciation of care is particularly evident in the case of Germany's elder care regime where the bulk of elder care is still unpaid and provided in private households or delegated to informal workers outside the family. What drives the depreciation of care work is not the direct pursuit of profit generation. Instead, attempts are made to indirectly protect profits by keeping care costs low. And this in turn is realised by the help of limited public budgets: Regarding "sector 1", driven by the cost pressure of low long-term care insurance, a price-cutting competition takes place that results in cutting wages and utilising migrants and unskilled care workers for informal care work. This depreciation can also be achieved by unpaid elder care work as in the case of family members and volunteers ("sector 2").

By mobilising these groups with the help of state care policy, their labour power can be appropriated cheaply compared to the costs of formally employed professionals. Government spending on elder care and employers' contributions to long-term care insurance can thus be kept at a comparatively low level. Small providers, who are suffering from cost pressure and a shortage of skilled workers, can also save on personnel costs without making profits. Thus, just as unpaid domestic work reduces the value of labour power and indirectly increases profits, unpaid and underpaid informal elder care work also indirectly increases profits, and contributes to the maintenance of a care regime geared towards cost reduction. In addition to the poorly remunerated and rationalised care work of formally employed professionals, it represents another effective strategy to keep reproduction costs low. More is said about this in the section below headed "Results".

\section{Theoretical Framework: Exclusion, Social Vulnerability and Depreciation}

The indirect exploitation of informal elder care is understood here as the process in which certain actors under specific conditions appropriate the depreciated labour efforts of socially vulnerable lay care workers to lower reproduction costs. Compared with the costs of formally employed professional care workers, this means especially cheap or even for free. According to Wright (1997: 10), whose definition of exploitation we follow here, exploitation can be defined by the help of three criteria. First, the material welfare of exploiters causally depends on the material deprivations of the exploited. Second, following "the exclusion principle", the causal relation involves the asymmetrical exclusion of the exploited from access to and control over important productive resources. This exclusion may be accompanied by force and oppression but in some cases it may not be. Third, the causal mechanism involves the appropriation of the fruits of the labour of the exploited by the exploiters.

According to Marx, expropriation and social power relations play a central role as conditions for exploitation. Thus, propertylessness and powerlessness on the part of the exploited mark the structural linchpin of their exploitability. But expropriation is a term mostly aimed at the ownership 
of economic means of production, such as land or machinery (Fraser, 2016: 166), and is thus alone not suitable for capturing specific cultural disadvantages associated with sexist or racial discrimination. Exclusion, which is widely used in German and French sociology (Dubet and Lapeyronnie, 1992), points to fundamental social divisions caused by unemployment, the loss of close social relationships and poverty in the Global North. Regarding the groups investigated here (especially the unemployed, poverty migrants or poor pensioners), and according to Wright, the term exclusion is used here instead of expropriation. However, compared to Wright, who also focused only on economic resources, the term is used here more openly regarding economic and cultural disadvantages, both of which are relevant to exploitation in highly feminised working contexts. Like expropriation, exclusion refers to social subject positions that are characterised by a specific lack of resources, but it can also highlight cultural disadvantages.

Furthermore, exploitation as a hierarchical power relation mainly goes hand in hand with oppression but is not identical with it. Oppression is a power-theoretical term essential for understanding relationships of exploitation. But in contrast to oppression, the specificity of the concept of exploitation lies in the appropriation of labour power (Wright, 1989: 77). To address the issue of highly feminised elder care work and to consider those special groups mobilised by Germany's elder care policy, we use a concept of exploitation, aided by the concept of exclusion, which acknowledges that "we are dealing with a capitalist mode of ... reproduction that entails historically specific relations of gender and racial oppression" (McNally, 2017: 111). Because exclusion and the related economic and cultural disadvantages mainly result from oppression (as specific relations of gender and racial oppression), it should always be considered as oppressive. However, as Wright correctly stated, exploitation must be distinguished from "nonexploitative oppression". ${ }^{5}$ We can make similar observations for the groups under investigation. Volunteers, for example, are not oppressed, but rather receive state support. Nevertheless, their involvement can be attributed to a lack of social recognition or economic resources, like sufficient pensions or wage income, due to their exclusion from the labour market. To sum up, instead of dealing with expropriation and oppression, we use the term exclusion as a first condition for exploitation, one which is sensitive to various forms of economic and cultural oppression and which emphasises dependencies that make certain groups of people economically exploitable.

The next step from exclusion to exploitation can be taken with the help of the subject-related term social vulnerability, which derives from research on informality (Alter Chen, 2013: 152). This is the second enabling condition for the exploitation processes examined here. Accordingly, social processes of exclusion generate social vulnerability in at least two ways, which can be specifically exploited. First, social vulnerability can be caused by material-economic scarcity, due to exclusion from access to the possession of assets and means of production, as well as through exclusion from wage labour or welfare compensations. Those cases result in material vulnerability, forcing the affected persons to make concessions, for instance, by accepting informal jobs. Second, social vulnerability is also generated in the cultural-symbolic sphere by discriminatory practices that cause exclusion according to gender, race, age and class. Cultural vulnerability also designates the condition in which individuals, depreciated by sexist or racist discrimination, are forced to accept low pay and informal jobs. The idea of cultural vulnerability acknowledges the central influence of multiple oppressions and socio-cultural factors on the constitution and reproduction of exploitative

${ }^{5}$ According to Wright (1997: 11), "the crucial difference ... is that, in an exploitative relation, the exploiter depends upon the effort of the exploited. In the case of nonexploitative oppression, the oppressors would be happy if the oppressed simply disappeared". 
relations, particularly as emphasised by social reproduction theory (Bhattacharya, 2017: 3). ${ }^{6}$

Last but not least, we need to consider the special situation of the elder care market in Germany. In contrast to Marx, exploitation in Germany's elder care market does not mainly arise in the form of productive labour directly creating profits. Instead, many providers depreciate elder care work by cutting wages due to the specific cost pressure based on the structure of long-term care insurance. Because the limited budgets of the insurance, laid down by the state, also determine the level of wages and the purchasing power of private households, the providers and even private households rely on especially cheap elder care. This in turn can take the form of the informal and often illegal use of paid unskilled assistants as well as in the use of unpaid volunteers or relatives. Both forms of state-subsidised informal labour are different from the capitalistically exploited formal and "productive" wage labour that Marx had in mind. Neither the illegal use of unskilled assistants nor support from volunteers or relatives is aimed at direct profit generation. Instead, their use keeps reproduction costs especially low compared to professional elder care. These savings contribute indirectly to increasing profits, because they keep employers' contributions to long-term care insurance low. This in turn means, and this will be shown in the following section, that very different actors - such as employers and the state, but also small providers and private households - are among the beneficiaries of this indirect exploitation.

To sum up, this concept of indirect exploitation combines Wright's "exclusion principle" with the Marxist-Feminist term depreciation and adds the term social vulnerability. It starts with multiple processes of exclusion that in turn lead to material as well as cultural vulnerability. These positions of social vulnerability can in turn be exploited with the aim of depreciating elder care work. Social vulnerability thus tries to combine exclusion with exploitation to integrate economic and cultural disadvantages equally. And depreciation understands that exploitation does not necessarily go hand in hand with surplus but can also have a negative value difference. Thus, we now have a concept of exploitation that, one, does not depend upon the direct creation of profits, and two, considers special social vulnerabilities due to economic and cultural disadvantages in the field of informal elder care. To illustrate some core mechanisms as well as the beneficiaries of this indirect exploitation, selected findings of a study will now be introduced.

\section{Study Methodology}

To analyse the mechanisms of exploitation of informal elder care work, a qualitative interview study was carried out from 2014 till 2016 (Haubner, 2017). The decision to undertake this type of study derived from the understanding that exploitation is a specific social relation that needs to be considered as culturally and socially embedded. Thus, the study did not attempt to be representative in a statistical sense. Instead, it aimed to identify the social and cultural mechanisms that structure exploitative relationships. Overall, twenty-seven semi-structured interviews were conducted,

\footnotetext{
${ }^{6}$ Nancy Fraser (2016: 166) tries in a very similar way to connect the economic logic and political order of capitalist societies. With the terms "expropriation" and "political subjectivation" she aims at the exploitation of unfree labour and the state-supported devaluation of certain groups of people. "Expropriation" refers to material aspects, specifically confiscated assets such as land, labour or energy deposits. To integrate racial discrimination, Fraser adds the term "political subjectivation". However, instead of analytically separating "free subjects of exploitation" from "dependent subjects of expropriation" (Fraser, 2016: 169), the term exploitation is used here for both paid and unpaid informal care work. The term social vulnerability also encompasses economically, politically and culturally inferior subject positions.
} 
mostly in the eastern parts of Germany. The interviewees comprised four groups - female relatives; volunteers; low-skilled "additional personal assistants"; and migrant care workers. Expert interviews were also carried out with nursing science experts, employees of the German Federal Employment Agency, and management from private and public nursing homes. Using theoretical sampling, the expert interviews and the interviews with informal elder care workers were evaluated separately with the help of MAXQDA 10. The two interview types were also triangulated to allow for different perspectives on the exploitation of elder care by those who exploited it (some of the experts) and those who actually did informal elder care work (family members, volunteers, migrant domestic workers and unskilled care workers). Finally, analyses of social reporting as well as representative studies on Germany's elder care regime were added to the investigation.

\section{Study Results}

\section{Intertwined vulnerabilities}

The question of who is exploited in the informal areas of Germany's elder care market and for what reasons can be answered with regard to the social vulnerabilities of the four study groups. Not uncoincidentally, socio-political support for unskilled and informal elder care work focuses on those mostly female parts of the population that are socially vulnerable due to processes of exclusion because of material-economic scarcity and discrimination practices. Almost all the interviewees of the four groups in our sample are socially vulnerable due to a lack of material resources. They are also mostly women who are considered "naturally" capable of caring for others without needing proper qualifications or payment.

Regarding the first group, relatives, the empirical findings from interviews with three female relatives show that the family-based elder care regime is not only rooted in the elders' desire for care by their own families but in the social vulnerability of the mostly female main caregivers. Regarding the aforementioned material vulnerabilities, female relatives provide most of the informal elder care because of low insurance benefits and insufficient professional care services. Because long-term care insurance only covers about half of the care costs incurred, relatives have always been forced to perform a large part of unpaid care work. Facing the alternatives - to use the help of an outpatient service, which carries out only the most necessary tasks at small intervals due to low insurance benefits, or to do the bulk of care work oneself only with the help of very low benefits (which are merely supplementary benefits and not wages) - the majority of relatives decide to receive the lowest cash-for-care benefits and take on sole care responsibilities. Thus, inadequate insurance benefits and low household incomes, which limit the purchase of professional care services, interact with each other. Cultural vulnerability also plays a role when wives, daughters or stepdaughters assume, on their own, overstraining care responsibilities due to both learned and ascribed care competence and family obligations. And they pay a high price: Up to 70 per cent of caring relatives (and that means mostly women) suffer from depression due to their care obligations (Deufert, 2013: 521). Germany's care regime is thus able to make strategic use of these ascriptive and internalised role attributions of female relatives. By forcing them to provide the bulk of home elder care alone and to risk poverty, reproductive costs can be reduced to ease the burden on the state budget and employers.

To provide incentives for the second group, volunteers, the state offers hourly compensation payments and training with the help of long-term care insurance benefits. The sample of three 
volunteer "dementia assistants" and the head of a volunteer agency shows that monetarised volunteer care work is now a small player in the elder care market, competing with outpatient services. It is also increasingly attractive for those with low incomes and is used as an additional source of income for female pensioners affected by poverty in old age. Material and cultural vulnerabilities come into play when volunteer work is used by the unemployed or working poor to earn some extra cash, to improve their employability, and to tackle the stigma of unemployment and poverty. In addition, volunteer work in the field of elder care is seen as "women's work", where predominantly older and retired women are involved due to gender-specific divisions of care work. The help of volunteers is taken up by private households that wish to relieve themselves by purchasing informal support subsidised by the state. It finally results from the limited financial options for many caring relatives who are urgently in need of cost-effective support.

For the third group, migrant care workers, the example of one Bulgarian care worker and a group of nine care workers from different Eastern European countries makes it drastically clear that social exclusion can result in social vulnerability, which in turn can give rise to exploitation. The specific economic vulnerability of Eastern European care workers derives from unemployment, especially for women, and the lack of welfare state protection. These materially and culturally vulnerable and often unqualified female migrant care workers end up taking care of heavily dependent people, mostly regardless of labour law provisions. Regarding cultural vulnerability, their informal care work is not only highly feminised, but also structured by discriminatory practices of ethnicisation, which finds symbolic expression in the so-called "24-hour Polish care worker"- praised by placement agencies as particularly family-oriented and hardworking.

Finally, public workfare programmes recruit formerly long-term unemployed and unskilled people to fill the gaps in the shortage of skilled labour. These government-funded jobs are targeted at materially and culturally vulnerable individuals who suffer from the stigma of long-term unemployment and are willing to make concessions in terms of low wages and unpaid additional work. As documented in the sample of three "additional personal assistants", all fell into long-term unemployment and poverty following German reunification and the end of the former socialist German Democratic Republic in 1989. Regarding cultural vulnerability, during the interviews with the German Federal Employment Agency, it appeared that low-skilled and unemployed women tend to be recruited on the grounds of "having a big heart", which appears to be more important for feminised care work than formal qualifications. Although, these "additional personal assistants" are only supposed to perform low-threshold care tasks, they are often illegally used in elder care. This illegal use results, however, from the need to save money and the shortage of skilled labour to which most providers are subject. In many cases, the informal use of care workers is the only option to keep the business going.

\section{The cascaded exploitation of lay care work}

Exploitation in Germany's elder care market occurs when female relatives administer medications because of low insurance benefits, when volunteers do housekeeping for an expense allowance, when migrant domestic workers do wound care and are available twenty-four hours a day, seven days a week for low cash payments, and when "additional personal assistants" replace elder care professionals in nursing homes without being paid like professionals. This indirect exploitation can be described as cascaded. The economic dilemma of elder care work, which is indispensable but of limited profitability, marks the beginning of the exploitation cascade. This basic economic problem is dealt with differently by national elder care regimes, with varying political framework conditions which address this economic dilemma in different ways. 
Germany's elder care regime is responding to the limited profitability of elder care with a specific cost pressure: The limited budgets of long-term care insurance create a structural exploitation pressure that is passed on down the chain onto the shoulders of actors with less and less scope for choice. Capped insurance rates put an ex ante limit on the available funding volume for all insurance benefits. The resulting financial pressure on household incomes and wages in care services is passed on to different care providers starting with ambulant and inpatient providers up to private households. Due to low care benefits and a lack of skilled workers, the providers surveyed have increasing difficulty recruiting professionals. Because of low wages, a lack of skilled labour and increasing demand, "additional personal assistants" are informally used and perform activities for which they are neither qualified nor paid. A more or less necessary recruitment strategy, it is also an exploitation mechanism in which the wage level is lowered through the illegal expansion of the work spectrum. However, this form of indirect exploitation is not aimed at generating profits. Rather, it aims at a specific depreciation of elder care work that in turn primarily results from limited financial volume. The profiteers of this exploitation benefit in very different ways: While the small care providers are only able to maintain their businesses despite financial bottlenecks, the big winners include the state and capital, who are not forced to respond to rising care costs by raising contribution rates and wages.

Regarding migrant care workers, even more exploitative instances come into play. It is not only private agencies that benefit from what is slavery-like exploitation. State and capital can also keep reproduction costs low with the illegal use of their labour, which sanctions neither exceeding competences nor working hours. Finally, private households are only able to purchase comprehensive home care by utilising the cheap or even free help of socially vulnerable relatives, volunteers or informally working migrant care workers. In the face of low insurance benefits, the households take advantage of the fact that lay care workers give injections, dress wounds, administer medication or keep house on the basis of expense allowances or low insurance benefits. Thus, private households must also be regarded as exploitative institutions, although their choice is often born of necessity. Finally, the thesis of an exploitation relation is also strengthened by the empirical finding of a transgression of qualifications, when lay care workers carry out care activities for which they are not qualified or paid. For example, the local success of a volunteer agency, whose volunteers informally provide wound care and domestic services during their missions, is based on the needs of old people, for whom professional care is often only available to a limited extent.

\section{Conclusion}

The socio-political expansion of informal elder care work in Germany has been examined here in terms of exploitation. The notions of exclusion and social vulnerability were used to answer the question why mainly women from special population groups are targeted by German care policy. In addition, the notion of depreciation has been used to sketch a nationally specific cascade of indirect exploitation dynamics which primarily occur due to state-driven cost pressure that in turn aims at keeping reproduction costs low. In doing so, the concept of exploitation is opened up to informal care work. Also, insights are gained into grey areas of the German elder care market that have not been much researched. Using the notion of indirect exploitation and giving equal consideration to economic and cultural mechanisms of exploitation, the cases examined here have tried to show that exploitation in ageing capitalist societies need not necessarily exist only in formal employment and due to the direct generation of profits. Instead, unpaid and underpaid informal 
care work is a constitutive element of a capitalist "work transfer", in which the depreciation of elder care work elsewhere expands the scope for economic action. "In health care", in other words, "the financial saving of shifting work to patients and their families is not reflected in reduced outof-pocket costs but in reduced costs to business and the federal government" (Glazer, 1993: 14). The use of informal lay care work is thus not a pre-capitalist remnant or merely a result of incomplete markets. Instead, it is actively politically promoted and used economically. One could of course also speak of a state-driven informalisation and deprofessionalisation of elder care. However, this would neglect the causal nexus we can observe here. To speak of exploitation means that state- and especially capital-run interests are taking advantage of socially vulnerable population groups for the purpose of lower reproduction costs. Because elder care is only marginally profitable but increasingly demanded, this exploitation reveals a structurally determined, yet actively pursued political strategy of labour utilisation that indirectly increases profits from certain actors' social vulnerability. Finally, this investigation widens the scope of struggles in the workplace to those hidden areas of care work that have long been ignored. Thus, it also allows research on exploitation processes in other fields of care services. The use of volunteers, as currently promoted by social policy in Germany, can also be analysed in terms of exploitation in the areas of family support, allday school care or neighbourhood assistance.

\section{REFERENCES}

Alter Chen, M. (2013) Informalität, Geschlecht und die globalen Auswirkungen der großen Rezession. In Arbeit in globaler Perspektive. Facetten informeller Beschäftigung, edited by H.-J. Burchardt, S. Peters and N. Weinmann. Frankfurt a. M. and New York: Campus.

Bartlett, W., A.J. Roberts and J. Le Grand (eds.) (1998) A Revolution in Social Policy. Quasi-market Reforms in the 1990s. Bristol: Bristol University Press.

Bauböck, R. (1988) Hausarbeit und Ausbeutung. Zur feministischen Kritik am Marx'schen Arbeitsbegriff. Report number 245. Wien: Institut für höhere Studien.

Baumol, W.J. (2012) The Cost Disease. Why Computers Get Cheaper and Health Care Doesn't. New Haven, CT: Yale University Press.

Bhattacharya, T. (ed.) (2017) Social Reproduction Theory. Remapping Class, Recentering Oppression. London: Pluto Press.

Biesecker, A., C.v. Braunmühl, C. Wichterich and U.v. Winterfeld (2007) Die Privatisierung des Politischen. $\mathrm{Zu}$ den Auswirkungen der doppelten Privatisierung. Femina Politica. Zeitschrift für feministische Politikwissenschaft, 16(2): 28-41.

Bock, G. and B. Duden (1977) Arbeit aus Liebe - Liebe als Arbeit: Zur Entstehung der Hausarbeit im Kapitalismus. In Frauen und Wissenschaft. Beiträge zur Berliner Sommeruniversität für Franen, Juli 1976, edited by Gruppe Berliner Dozentinnen. Berlin: Courage-Verl.

Deufert, D. (2013) Genderaspekte in der Angehörigenpflege. Zeitschrift für Gerontologie und Geriatrie, 6(46): $520-525$.

Dubet, F. and D. Lapeyronnie (1992) Les quartiers d'exil. Paris: Seuil.

Etzioni, A. (1969) The Semi-professions and their Organization: Teachers, Nurses, Social Workers. New York: The Free Press.

Federici, S. (2009) Anmerkungen über Altenpflegearbeit und die Grenzen des Marxismus. In Über Marx binaus. Arbeitsgeschichte und Arbeitsbegriff in der Konfrontation mit den globalen Arbeitsverbältnissen des 21. Jahrbunderts, edited by M. van der Linden and K.H. Roth. Hamburg: Assoziation A.

Federici, S. (2017) Notes on Gender in Marx's Capital. Continental Thought \& Theory, 1(4): 19-37. 
Fraser, N. (2016) Expropriation and Exploitation in Racialized Capitalism: A Reply to Michael Dawson. Critical Historical Studies, 3(1): 163-178.

Glazer, N.Y. (1993) Women's Paid and Unpaid Labor. The Work Transfer in Health Care and Retailing. Philadelphia, PA: Temple University Press.

Haubner, T. (2017) Die Ausbeutung der sorgenden Gemeinschaft. Laienpflege in Deutschland. Frankfurt a. M. and New York: Campus.

Le Grand, J. (1991) Quasi-Markets and Social Policy. The Economic Journal, 101(408): 1256-1267.

Marx, K. (1887) Capital. A Critique of Political Economy. Vol. 1. The Process of Production of Capital. Moscow: Progress Publishers.

Mayer-Ahuja, N. (2012) Arbeit, Unsicherheit, Informalität. In Kapitalismustheorie und Arbeit. Neue Ansätze soziologischer Kritik, edited by K. Dörre, D. Sauer and V. Wittke. Frankfurt a. M. and New York: Campus.

McNally, D. (2017) Intersections and Dialectics: Critical Reconstructions in Social Reproduction Theory. In Social Reproduction Theory. Remapping Class, Recentering Oppression, edited by T. Bhattacharya. London: Pluto Press.

Powell, M. (2007) The Mixed Economy of Welfare and the Social Division of Welfare. In Understanding the Mixed Economy of Welfare, edited by M. Powell. Bristol: Policy Press.

Prognos AG (2012) Pflegelandschaft 2030. http://www.prognos.com/uploads/tx_atwpubdb/121000 Prognos vbw Pflegelandschaft 2030.pdf [accessed 3 December 2020].

Statistisches Bundesamt (2018) Pflegestatistik. Pflege im Rahmen der Pflegeversicherung. Deutschlandergebnisse. https://www.destatis.de/DE/Themen/Gesellschaft-Umwelt/Gesundheit/Pflege /Publikationen/Downloads-Pflege/pflege-deutschlandergebnisse-5224001179004.pdf?_blob= publicationFile [accessed 3 December 2020.

Wright, E.O. (1997) Class Counts. Comparative Studies in Class Analysis. Cambridge: Cambridge University Press.

Wright, E.O. (1989) Classes. London and New York: Verso.

\section{DISCLOSURE}

The author received no financial support for the research, authorship and/or publication of this article.

\section{BIOGRAPHICAL NOTE}

Tine HAubNeR works as a scientific assistant at the Department of Sociology at the Friedrich Schiller University of Jena, Germany. [Email: Tine.Haubner@uni-jena.de] 